\title{
OLHARES CRUZADOS SOBRE ARTE, IMAGEM E RESISTÊNCIAS URBANAS
}

\author{
Ricardo Campos ${ }^{1}$ \\ José Luís Abalos Júnior ${ }^{2}$ \\ Daniel Meirinho ${ }^{3}$
}

A cidade é alvo de constante atenção por parte dos investigadores em ciências sociais. O meio urbano tem sido pesquisado como palco onde se registam formas específicas de habitarmos o território e de nos relacionarmos com os outros, sendo frequentemente entendido como potenciando estilos e modos de vida específicos ao meio metropolitano ${ }^{456}$. O fato de estarmos perante ambientes humanos fortemente edificados e tecnologizados, populosos e diversificados do ponto de vista social, econômico, cultural e étnico, torna a cidade um laboratório central para o estudo da vida social, como afirmou Robert Park (1967), autor da Escola de Chicago, na década de 50 do século passado. Apesar das cidades terem mudado muito, esta afirmação continua ainda bastante atual e pertinente. $\mathrm{Na}$ verdade verificamos que grande parte daquilo que são problemas entendidos como tipicamente urbanos persistem, fato que justifica que, ao longo do tempo, um conjunto de temáticas e objetos de estudo se tenham afirmado como centrais para as ciências sociais que estudam a vida urbana.

\footnotetext{
${ }^{1}$ Universidade Nova de Lisboa, Portugal. Email: rmocampos@yahoo.com.br ORCID id: https://orcid.org/0000-0003-4689-0144

${ }^{2}$ Universidade Federal do Rio Grande do Sul, Brasil. Email: abalosjunior@gmail.com ORCID id: https://orcid.org/0000-0003-2821-0969

${ }^{3}$ Universidade Federal do Rio Grande do Norte, Brasil. Email: danielmeirinho@hotmail.com ORCID id: https://orcid.org/0000-0002-4658-5556
}

\footnotetext{
${ }^{4}$ Nota do autor Ricardo Campos: O presente trabalho foi realizado no âmbito do projeto "Juventude e as artes da cidadania: práticas criativas, cultura participativa e activismo - PTDC/SOC-SOC/28655/2017", da Fundação para a Ciência e Tecnologia (FCT), Portugal

${ }^{5}$ Nota do autor José Luís Abalos Junior: O presente trabalho foi realizado com apoio do Conselho Nacional de Desenvolvimento Científico e Tecnológico (CNPq) através da concessão da bolsa de PósDoutorado Júnior no projeto “As políticas da criatividade: revitalização urbana, empreendedorismo criativo e gentrificação no Quarto Distrito de Porto Alegre/RS".

${ }^{6}$ Este dossiê é o resultado de uma parceria de internacionalização da pesquisa iniciada em 2017 com a presença de Ricardo Campos na cidade de Porto Alegre/RS junto ao Núcleo de Antropologia Visual (NAVISUAL/PPGAS/UFRGS). Desta parceria renderam muitas articulações, como o projeto de Doutorado Sanduíche de José Luís Abalos Júnior (CAPES/PDSE/2018) em Lisboa sob a supervisão de Ricardo Campos. Desde então esse dossiê é idealizado como um resultado desta parceria entre Brasil e Portugal.
} 
Uma das questões que mais pesquisas e debates têm suscitado é relativa à cidade como terreno de ação política. Verificamos que os grandes movimentos sociais, as formas de resistência, às revoluções ou os episódios de protesto ocorrem na grande maioria das vezes nas cidades e particularmente nas grandes metrópoles. Por tradição, é no espaço público urbano que os movimentos sociais se manifestam, afrontam o poder e ganham combates. Mas é também neste espaço que indivíduos anônimos, grupos espontâneos e menos estruturados encontram um lugar para participarem do ponto de vista cívico e político. A política do cotidiano e dos ausentes das estruturas de poder exerce-se na esfera não-formal e, aqui, a cidade é de especial relevo. As reivindicações, mobilizações e ocupações, são gestos políticos protagonizados geralmente por aqueles que se encontram à margem do sistema político convencional, sejam associações ou coletivos mais ou menos informais, sejam indivíduos sem militância particular.

No espaço urbano assiste-se a uma participação política do cidadão que vai da micropolítica do cotidiano, que passa por operações táticas de resistência (De Certeau, 1998), até às formas mais intensas e violentas de protesto. A cidade é, assim, marcada sempre por um equilíbrio mais ou menos instável entre a ordem e a desordem, sendo que desta tensão resultam necessariamente impulsos disruptivos que, tantas vezes, operam ao nível do simbólico e do estético.

Uma dimensão que também tem estado frequentemente associada ao exercício da política e da cidadania em meio urbano é a relativa à estética, que atravessa distintos objetos empíricos (Campos, Pavoni e Zaimakis, 2021; Campos, 2021; Delgado, 2013). Podemos considerar neste domínio, por exemplo, as operações performáticas que estão presentes nos corpos coletivos e individuais que se movem, manifestam e expressam politicamente na cidade. Falamos de formas gregárias que assumem identidades visuais específicas, que geram performances de protesto altamente criativas, que funcionam como um corpo coletivo singular (Vergara, 2015). As manifestações e formas de protesto do black block ou dos extinction rebellion (Figura. 1) são um bom exemplo deste poderio da imagem e da performance que apesar de ter uma dimensão localizada se converte numa imagem de marca global destes movimentos. Para além destes fenómenos não podemos ignorar os recursos e dispositivos de combate político que recorrem a recursos estéticos, passando pela música, pela imagem e, cada vez mais, por dispositivos digitais (Aderaldo e Raposo, 2016; Aderaldo, 2017; Campos, Simões e Pereira, 2018; Juris, 2015). A este respeito convém destacar a imagem que é produzida através de recursos simples e económicos, que se encontra nos cartazes das manifestações (Figura. 2), no stencil e 
graffiti existente nas ruas (Figura.3), mas igualmente nas filmagens digitais que em streaming ou em registo assíncrono criam momentos virais e memórias audiovisuais das dinâmicas políticas coletivas.

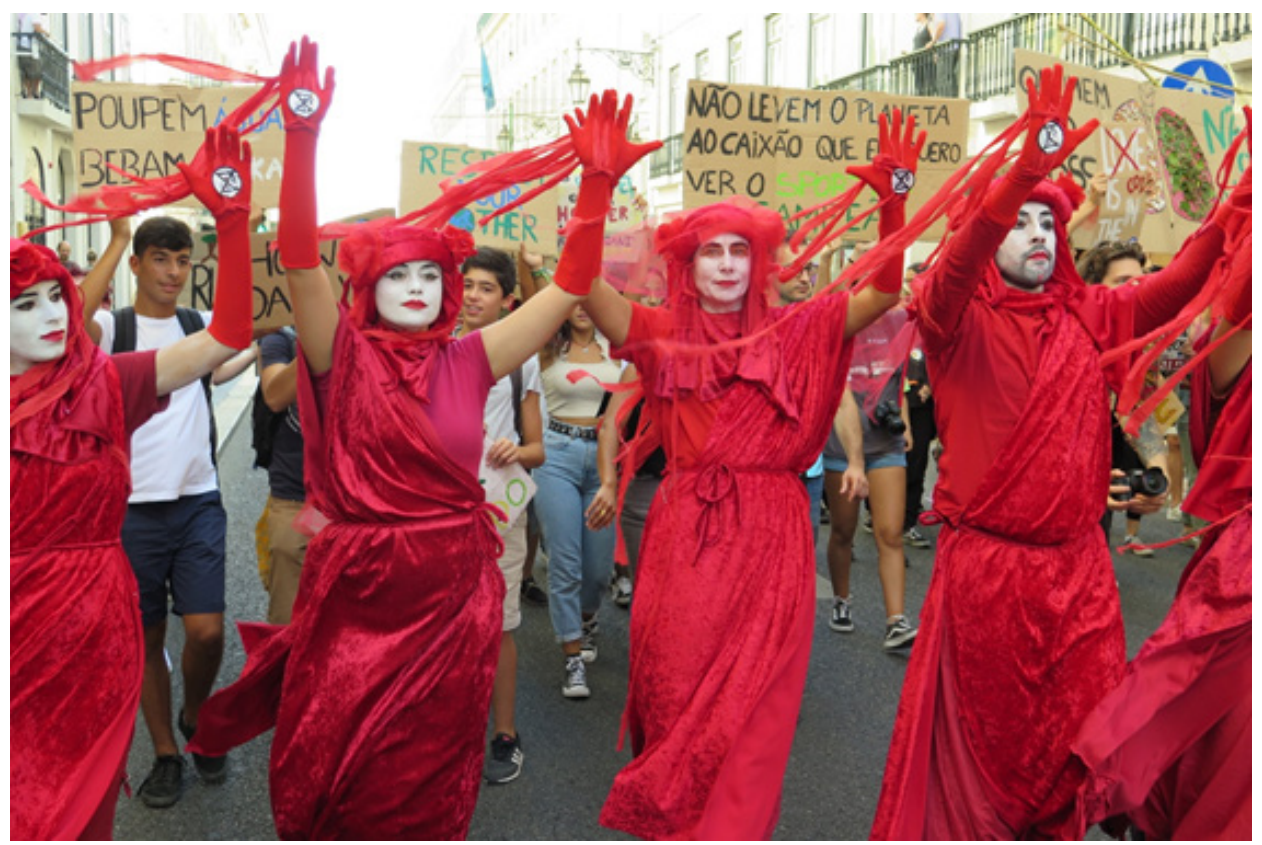

Imagem 1: Greve climática juvenil, Extinction Rebellion Portugal (Lisboa, 2019). Autor: Ricardo Campos

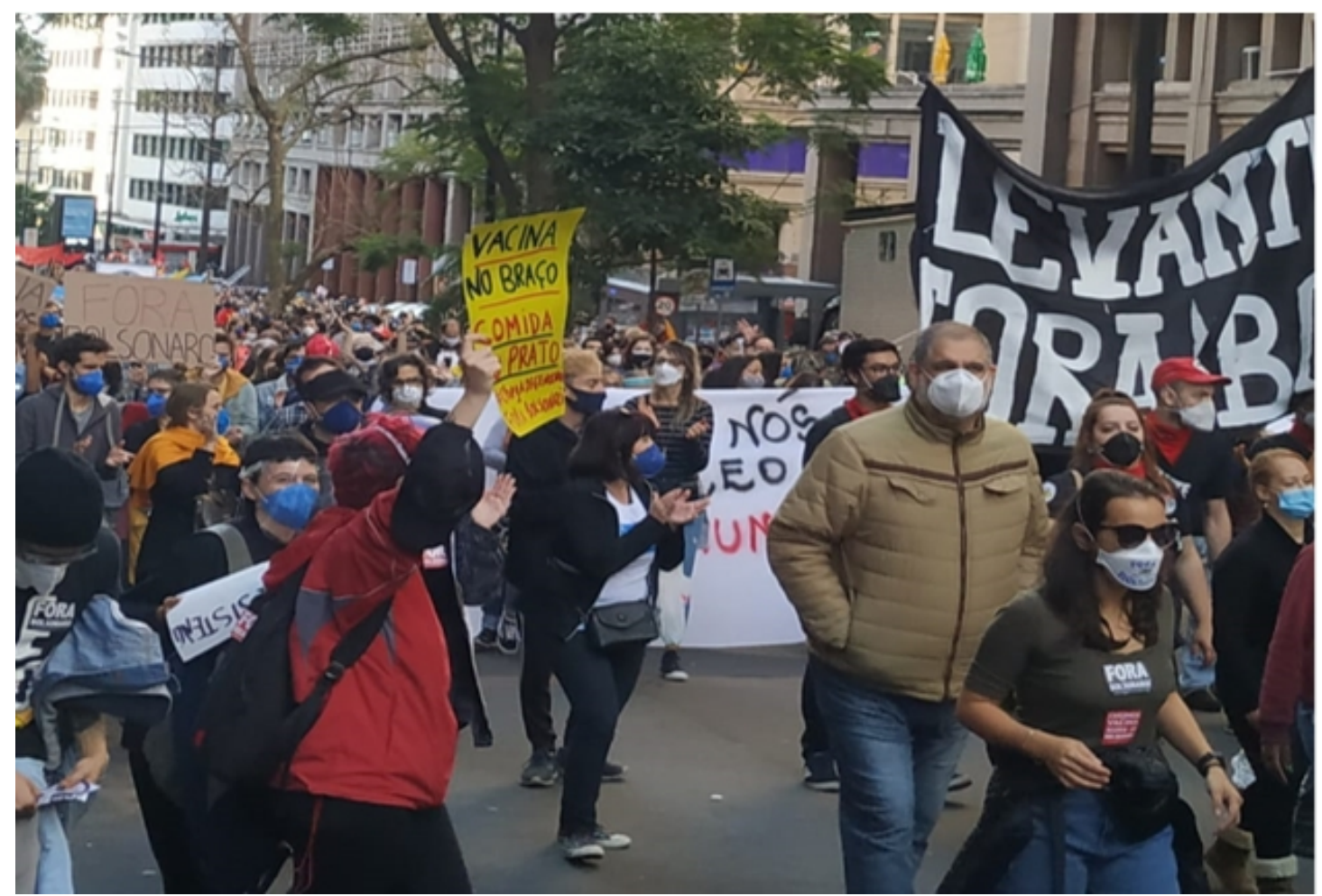

Imagem 2: Cartazes de Manifestação de 29 de Maio de 2021 (\#29M) em Porto Alegre. Autor: José Luís Abalos Júnior 


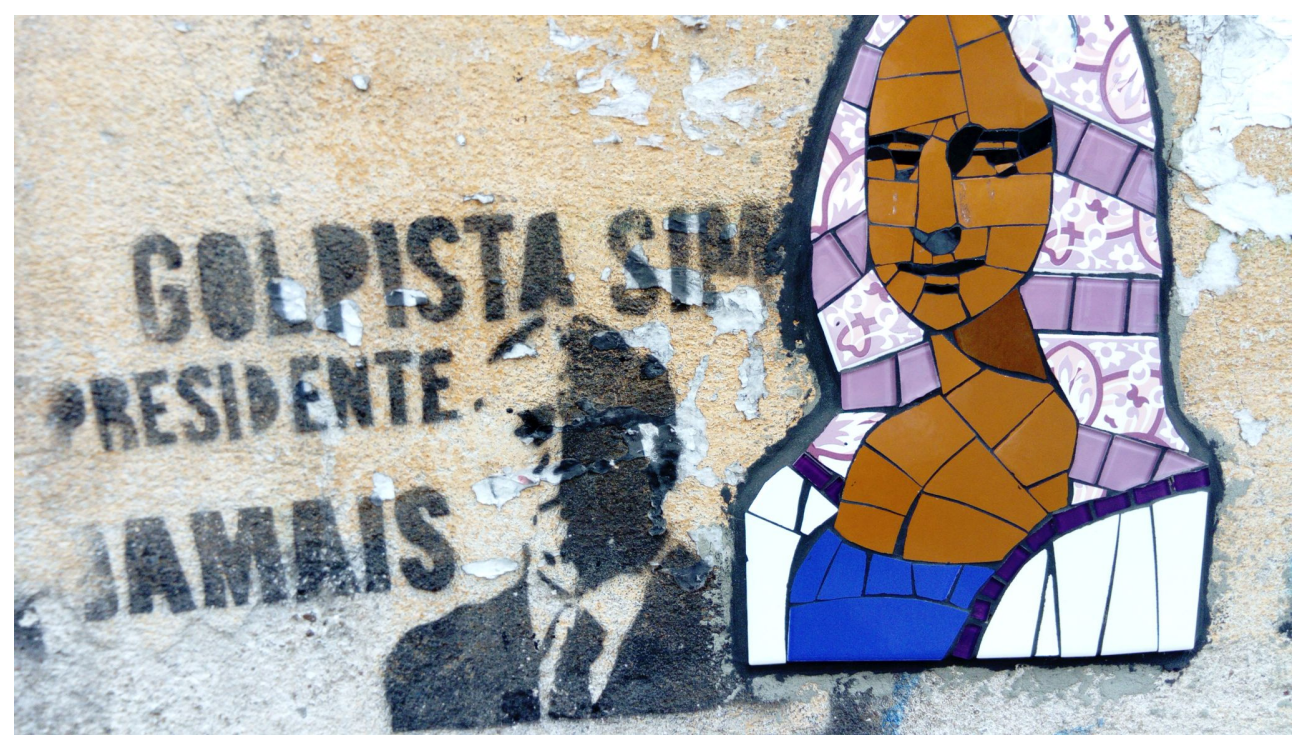

Imagem 3: Stencil com referência a Michel Temer (Porto Alegre, 2017). Autor: Ricardo Campos

Mas a arte e a estética também têm sido empregues com propósito político por parte do poder. O poder manifesta-se na ocupação do espaço, na ostentação, na vigilância e na disciplina, mas também na arte pública de regime, que enaltece certos valores, heróis e episódios históricos emblemáticos. Não é de estranhar, então, que após revoluções ou processos violentos de mudança de poder, exista uma enérgica atividade de remoção dos símbolos e artes associadas ao anterior regime.

A arte e a criação estética têm-se revelado, ao longo da história, como dispositivos não apenas de usufruto e prazer dos sentidos, mas também de diálogo e dissenso político (Di Giovanni, 2015; Raposo, 2015). Forma de propaganda ou de resistência, a arte é empregue por diferentes lados da barricada, ora instrumentalizada pelos poderosos, ora arma de arremesso dos subalternos e oprimidos. Importa, por isso, olhar para o terreno da política não-formal, para exercícios de cidadania e ativismo que acontecem à margem da política eleitoral e partidária. Vários estudos têm vindo a demonstrar um gradual afastamento da política institucional por parte das novas gerações, crescentemente descrentes da capacidade do sistema em dar voz às suas preocupações. E são precisamente os mais jovens que mais recorrem a canais e formas de comunicação alternativas, expressando-se politicamente através de exercícios de natureza criativa e estética (Campos e Sarrouy, 2020).

O tema da criatividade é outro elemento constante que aparece tanto nas narrativas de planejadores urbanos, quanto nas dos movimentos sociais. A percepção de que a criatividade além de ser uma prática político-estética é, também, uma forma discursiva 
está presente em várias referências contemporâneas através de linguagens de governança, mas também de resistência (Mould, 2015; Eckard, 2018; Abalos Júnior, 2021). Essa criatividade narrada, vivida e estetizada aparece em inúmeras formas de subversão urbana, mas também enquanto política urbana normativa e regulada na instauração de territórios criativos. O que percebemos é uma retórica da criatividade presentes em muitos níveis, desde de uma cidade planejada até uma cidade praticada (De Certeau, 1998).

Ao pensar em arte, imagem e resistência urbanas podemos dizer que estamos pensando junto com o antropólogo francês Michel Agier no que denominou de "fazercidade" (2015). A cidade é feita de fluxos, mobilidades e movimentos que trazem uma dimensão projetiva na qual os habitantes da urbe desejam um modelo de cidade e se mobilizam em prol desse desejo. Seja artistas, moradores ou planejadores, todos produzem a cidade nas suas maneiras de idealizar uma forma desse urbano. Aqui é interessante verificar como isso está representado nas imagens de um fazer-cidade vinculados à formas de resistência e qual o papel da arte nos processos de idealização de um urbano em constante contradição e mudança.

Esta problemática, que nos move em torno deste dossiê, não é propriamente original. Vários autores têm vindo precisamente a destacar a dimensão da criatividade e da produção estética, quer para exercícios de micro-política no cotidiano, quer para ações mais episódicas de protesto. Este olhar sobre diferentes formas de conceber e praticar o político, têm dado origem a conceitos como os de: artes da cidadania (Campos e Sarrouy, 2019), artivismo (Sandoval e Latorre, 2008) democracia criativa (Hankins, 2017), cidadania criativa (Hargreaves e Hartley, 2016), estéticas de protesto (BUSER, et al 2013), carnavais de protesto e "protestivais" (St. John, 2008), ativismo criativo (Harrebye, 2015), entre outros. Pelas diferentes razões invocadas anteriormente, o meio urbano é o palco privilegiado onde estas expressões ganham vida.

\section{Estratégias de expor sem ser exposto}

No Brasil, bem como em muitas outras regiões do mundo que encontram-se sob contextos de intolerância e exploração, artistas e ativistas congregam um desejo comum de que suas práticas discursivas, narrativas e estéticas possam vir a se articular de forma crítica com os problemas de nosso tempo (Rosas, 2015). O próprio movimento de artivismo, já apresentado anteriormente, tem se apropriado das mídias, das tecnologias e da rua para produzir novas formas de intervenção artísticas. Entendemos como formas de 
operacionalizar práticas transformadoras que vão pensar as lutas sociais de maneira situada. Como afirmou Suely Rolnik (2008), sempre houve convergências entre arte, política e movimentos sociais do século XX na história da arte, o que muda é a percepção pela qual compreendemos essas convergências ou buscamos nomeá-las (Gonçalves, 2012).

Entre as múltiplas estratégias de ativismo e contestação (Ferreira Da Silva, 2020) utilizadas para ativar lutas e causas sociais, políticas e identitárias, a arte pode ser compreendida como uma forma e estetizar alguns dos pólos de conflito que envolvem marcadores de classe, raça, etnia, gênero, religião, etc. Artistas e poéticas, a partir de suas práticas, organizam assim suas presenças e corporificações com base nas modelações “estéticas relacionais" (Bourriaud, 2009: 21) de interpretacão e entendimento, ao aproximarem a arte das dimensões micro e macropolíticas.

Para Rolnick (2008), as táticas ativistas das ações macropolíticas se materializam em uma cartografia visível que delimita sujeitos, objetos e suas representações. O poder de reverberação desta dimensão pela arte é que organiza a maneira das coisas estarem visíveis no mundo, tanto em larga escala como em um sentido de entendimento simbólico micropolíticas a partir de códigos pelos quais organizamos como as coisas podem ser mostradas ao mundo. (De Certeau, 1998). As ações coletivas de luta, já bastante reconhecidas, como manifestações e protestos de rua são combinadas com ações menores e mais sutis que atuam e se anunciam no campo do sensível.

As duas estratégias ativistas no território da arte têm lugar e importância. A cidade como lugar deste confronto (Ferreira Da Silva, 2020) torna-se o cenário onde o jogo de ferramentas de libertação é combinado. O território público é o lugar de recusa e desmonte das formas institucionais de representação que universalizam a experiência, os modos e os discursos de sujeitos subalternizados. Assim, o ativismo artístico tem se ocupado em pensar outras formas de sensibilidade e conhecimento. A experiência local faz sentido quando se torna necessária a busca de múltiplas identidades possíveis (Tlostanova, 2011; Mignolo, 2010). Contestar um regime de representação se torna parte desta existência (Hall, 2016).

Neste estado de significado, que as coisas vão ter em um certo contexto, cada lugar, sujeito e território acaba criando um jeito participar de modular a experiência e a própria representação. Assim, surge ainda a possibilidade e o direito à decisão dos artistas ativistas de exporem-se e não serem expostos ou públicos às formas de exploração e exposição. Enquanto Glissant (1990) já nos alertava que nem tudo precisa ser enunciado 
de forma transparente, Jota Mombaça (2020) desvela, nos dias atuais, a importância de questionarmos o regime de expropriação de corpos e territórios pelo sistemas de arte. A opacidade enquanto estratégia criativa e imaginativa "prefigura o real sem determiná-lo a priori" (Glissant, 1990: 54).

Assim, a decisão de tornar-se público sem se expor, a partir de suas agendas ativistas, tem colocado alguns artistas em confronto com esse sistema de modulação interpretativas. A estética relacional da arte (Bourriaud, 2009) obriga a complexa articulação contemporânea dos conflitos contextuais, de sua geolocalização e dos múltiplos lugares de subjetividades. Os territórios, as memórias e as trajetórias artísticas ativistas apresentadas pelos artigos deste dossiê fazem parte deste campo de tensionamentos. Nos interpela um consenso limitador de quais os espaços são estabelecidos e destinados para as obras de arte, quem é o sujeito e quem é o artista na contemporaneidade? Nos leva a questionar a estética e a própria arte, em sua dimensão político-ativista, para assim percebermos que o campo da representação não é estático e os territórios simbólicos estão ainda ávidos por novos padrões emergentes.

Propostas artísticas ativistas como a de Denilson Baniwa (Figuras 3 e 4) mostram que a arte ativista e as resistências imagéticas podem não querer apenas resistir, mas sim propor um novo exercício imaginativo de confronto (Ferreira Da Silva, 2020). Suas obras, intervenções e performances propõem um outro regime de visibilidade e de exposição pública fugitiva (Moten e Harney, 2016) que desprograma a tal norma, negociando sua presença pública, sua representação e sua existência.

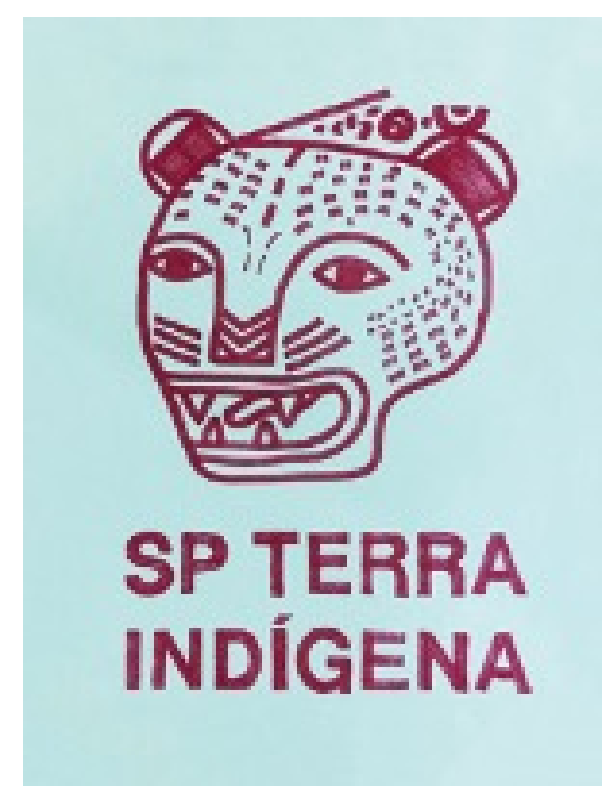

Imagem 4: Terra Indígena, impressão em papel lambe-lambe, tamanhos variáveis, 2018 (Denilson Baniwa) 


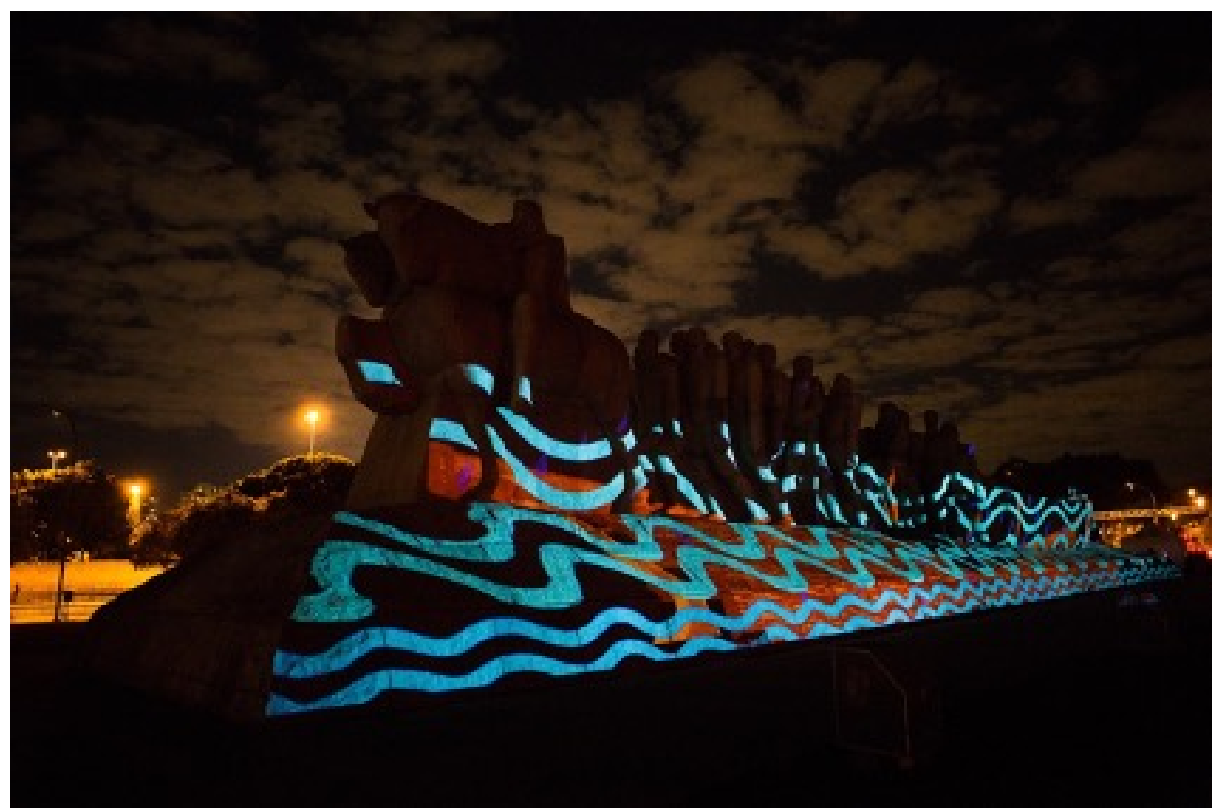

Imagem 5: "Brasil Terra Indígena" Projeção no Monumento às Bandeiras, São Paulo, 2020 (Denilson Baniwa)

Deslocar a ideia de presença de uma obra em um circuito, um território ou uma estrutura de modulação interpretativa, trata-se de impor novas alianças entre a arte e o ativismo. A rua, os monumentos e os circuitos específicos invertem, neste sentido, os territórios institucionais da arte. São contextos e dimensões políticas emergentes que ao mesmo tempo que se expõem publicamente correm o risco de se anular e de despotencializar a ação arte-ativista. A questão de expor sem ser exposto é a apresentação em recusa à simples representação que reitera os estereótipos e pode ser recusada.

\section{Um percurso artístico-imagético sobre formas de resistências urbanas}

Nesse dossiê o leitor encontrará o atravessamento de debates sobre territórios, biografias e movimentos. A importância e a potência dos lugares enquanto epicentros da vida artística, social e cultural aparece já nos primeiros artigos do dossiê. Em seguida podemos perceber o valor dado às trajetórias sociais de artistas que realizam intervenções urbanas nas suas múltiplas possibilidades. Por fim, em um dossiê com tal temática não poderiam faltar textos com o tema das associações coletivas em forma de marchas e protestos. Estes acontecimentos são representativos de movimentos pelos quais as pesquisadoras tiveram um olhar atento aos seus processos de construção. 
A imagem da capa é uma fotocolagem da artista visual cearense Mirian Ferreira, residente na cidade de Fortaleza. Em seu projeto Bendita Colagem Preta ${ }^{7}$ trabalha com fotocolagens a partir da tensão presente em corpos racializados a partir de suas reexistências e intervenções visuais, como parte do processo de subversão estética. Seu trabalho foi feito diretamente para esse dossiê como uma alegoria de como ações políticas congregam uma multiplicidade de questões e sujeitos, a partir da arte, da imagem e das resistências urbanas.

Na primeira dimensão, nas quais se encontram pesquisas que trouxeram um olhar para os territórios, iniciamos o dossiê com três artigos que tiveram como centro de estudos a cidade Fortaleza, no Ceará. Em “Artes de intervenção, inventar cidades” Deisimer Gorczevski, Aline Mourão Albuquerque e João Miguel Diógenes de Araújo Lima relatam experiências de pesquisa do Laboratório de Artes e Micropolíticas Urbanas (LAMUR) procurando os sentidos de "Fortalezas Sensíveis" se questionando sobre a existências de territórios geopolíticos. O texto é rico em referências teórico-metodológicas demonstrando possíveis "modos de intervir e pesquisar COM". O que nos leva a compor diferentes técnicas de pesquisa quando falamos em arte, imagem e resistências urbanas.

O Poço da Draga em Fortaleza, Ceará, é a espacialidade pesquisada pelos dois artigos que seguem no dossiê. Em "Resistência individual e memórias coletivas em álbuns fotográficos no Poço Da Draga/Fortaleza-CE” Cristina Maria da Silva e Francisco Felipe Pinto Braga se debruçam sobre os acervos fotográficos pessoais e o quanto estes, além de representar biografias individuais, podem ser entendidos enquanto uma materialização sensível da biografia da cidade. Já em "Comunidade visível: narradores de memórias e suas práticas de imagem” Felipe Camilo Mesquita Kardozo e Glória Maria dos Santos Diógenes trabalham com "práticas de imagem" ao encontro do uso de dispositivos técnicos e de uma antropologia compartilhada a partir do estudo de um antigo clube de futebol do território.

As dimensões de memória das resistências urbanas também fazem parte de um arsenal de possibilidades de pesquisas que fogem de uma dimensão unicamente presenteista. Neste sentido, contamos com o artigo de Leandro Lage e Júlia França denominado "Os fantasmas do levante cabano: entre o heroísmo do sujeito revoltado e a ira das multidões sediciosas" que aborda a dimensão histórica das formas de ação política. Ora chamado de revolta, ora chamado de revolução o "levante cabano" tem uma

\footnotetext{
${ }^{7}$ Ver em https://www.instagram.com/benditacolagempreta
} 
iconografia que nos remete à elementos estético-expressivos em uma emergência fantasmática, intermitente, mas, sobretudo, persistente e sobrevivente. Portanto, neste trabalho podemos observar a sobrevivência de gestos e afetos de resistência política dos sujeitos e povos amazônicos.

Continuando na reflexão sobre as dinâmicas de territórios a Praça do Povo (Brasília - DF) e a Praça do Cidadão (Ceilândia - DF) são os lugares escolhidos por Lorena da Silva Figueiredo e Gabriela Pereira de Freitas no trabalho "O lugar de encontro nas praças públicas do Distrito Federal: as intervenções artísticas pelos afetos”. Partindo da ideia de que saberes filosóficos, sociais e arquitetônicos se unem na compreensão da produção de subjetividades das intervenções artísticas, as autoras abordam uma “corporização afetiva do espaço público". O resgate de um sentimento de pertencimento à cidade pode ser acompanhado por ferramentas com a cartografia social que, como indicado neste artigo, pode ser um instrumento interessante de trabalho no estudo de arte e sociabilidades urbanas.

Seguindo os caminhos do dossiê são apresentados a trajetórias de artistas como Eder Oliveira, Sophie Calle e Ana Alvarez-Errecalde. O deslocamento da dimensão dos territórios para as questões biográficas de artistas diz respeito a um movimento amplo: o papel das trajetórias sociais nos estudos sobre arte, imagem e resistências urbanas. Assim, compreendemos este e estas artistas como testemunhos da cultura e da estética que marcam a paisagem citadina (Simmel, 1998). Também é interessante perceber suas ocupações em um lugar político central nas negociações e táticas para a "entrada em campo", mediando relações de alteridade.

Nesse cenário, o texto de Maria Cristina Simões Viviani e Rômulo Fonseca Morais abordam relações entre arte e colonialidade do poder no artigo "O corpo racializado nos muros da cidade: imagem e decolonialidade nas intervenções urbanas de Èder Oliveira". O artista paraense desloca as imagens/rostos de jovens negros que aparecem nas páginas policiais de jornais para os muros da cidade. Nesse novo espaço de visibilidade pública os rostos (feitos em grande escala) tomam sentidos distintos daqueles midiatizados. Segundo os autores, o artista chama atenção para os efeitos da colonialidade nos corpos racializados pelo processo colonial numa tentativa constante de reumanizar o desumanizado. 
A temática do gênero ${ }^{8}$ é outra que associa as resistências em forma de trajetórias sociais de mulheres nesse dossiê. Em "As flanâncias urbanas de Sophie Calle: reflexões entre público e privado" a autora Carolina Gallo Garcia tem como objeto de análise as imagens produzidas em performances realizadas nas décadas de 1980 e 1990 pela artista francesa Sophie Calle (1953) especificamente nos espaços públicos urbanos, considerando-os registros que interpreta como uma atualização de cunho feminista da flânerie baudelariana. Já em "La fotografía de Ana Álvarez-Errecalde: el reciclaje de las formas en la construcción de sentido e identidade" os autores Isabel Imbaquingo Pérez e Carlos H. Aulestia Páez aborda a obra da artista visual argentina enquanto uma expressão em que se materializa a contraposição política frente a valores estéticos. Este trabalho fotográfico pode ser entendido como uma mensagem estético-política que visa uma simetria entre a artista e o público que consome sua arte.

Cabe a ressaltar a importância que o filósofo francês Jacques Rancière (1998; $2000 ; 2002 ; 2008 ; 2014)$ toma em muitos referenciais teóricos dos artigos aqui presentes. Visto os estudos do autor sobre estéticas, políticas e dissensos, sua obra parece tomar uma relevância profunda na produção contemporânea sobre arte, imagem e resistência urbanas. Sem dúvida a obra “A partilha do sensível” (2000) é mais citada, porém nesse dossiê podemos ver reflexões sobre "O espectador emancipado" (2008), "Nas margens do político" (2014), "O desentendimento: política e filosofia" (1998), "O mestre ignorante" (2002), entre outras obras.

O tema dos protestos também se fez presente nesse dossiê nos dois últimos trabalhos. Em "Protestos e marchas de mulheres em Brasília: visualidades e estéticas" as autoras Luciana Ceschin e Virgínia Tiradentes Souto abordam como protestos podem ser uma forma de interpelar visualmente a paisagem das cidades. Atentas a dimensão de gênero presente em cartazes e símbolos destas marchas protagonizadas por mulheres, se observa que, além do repertório visual clássico das manifestações, há uma multiplicidade de estéticas como a da violência, do empoderamento, da festa, da provocação e as estéticas identitárias.

Finalizando o dossiê a autora argentina Marta Flores nos brinda com o artigo “Trabajo detrás de los símbolos de la protesta. Una etnografía de las marchas docentes. (Neuquén 2017-2018)", na qual realiza um acompanhamento etnográfico junto aos

\footnotetext{
${ }^{8}$ Todos os trabalhos apresentados neste dossiê têm mulheres como autoras e/ou co-autoras, o que representa uma partição massiva de investigadoras nos temas da arte, imagem e resistência urbanas.
} 
protestos organizados por "artistas-docentes". Tendo uma atenção especial aos símbolos e suas representações práticas e musicais, a autora revela um lado ritualístico na produção de protestos. Trata-se de uma etnografia de um ritual político-artístico de contestação carregado de diversos símbolos que em muito se associam ao tema das resistências urbanas.

Além dos artigos, quatro ensaios visuais abordam, de diferentes formas, a relação entre arte, imagem e resistências urbanas. A presença deste tipo de publicação no dossiê diz respeito a um espaço tradicionalmente aberto da Revista Iluminuras para publicações de narrativas, nas suas múltiplas possibilidades de mídia. Aqui encontramos dois ensaios em forma de narrativa fotográfica e outros dois na perspectiva do desenho enquanto forma de escrita etnográfica. Tais ensaios culminam em formas distintas de apresentar o tema da arte, da cidade e das resistências, assim como apresentam novos olhares ao tema proposto pelo dossiê.

No que diz respeito aos ensaios fotográficos, em "O ruído que brota dos muros do Porto: ensaio visual sobre o direito à habitação" a autora Inês Barbosa traz uma produção visual sobre intervenções urbanas que dialogam com o tema do direito à cidade (Lefebvre, 2006). As imagens dão conta das tensões e contradições associadas aos processos de gentrificação e turistificação na cidade do Porto, em Portugal. Já Jean Souza dos Anjos e Lara Denise Silva retratam em "Praia do Futuro - entre ruínas e resistências" um território marcado pelas estéticas das artes em tempos de pandemia. Interessante perceber o papel político e afetivo que as "desimportâncias" têm nesta narrativa visual apresentando graffitis, paredes derrubadas, ninhos escondidos, etc.

Os trabalhos com desenhos ocupam as duas últimas publicações deste dossiê. Em "Possibilidades do desenho à mão na etnografia urbana: estudo de caso em FlorianópolisSC" os autores Guilherme Ruchaud e Louise Prado Afonso demonstram o importante papel que o desenho pode ter na escrita etnográfica. Entre desenhos feitos rapidamente e produções mais elaboradas, o ato de desenhar pode acompanhar o etnógrafo que pensa formas de sistematizar seu conhecimento sobre o território. Já em "Cartografando desejos: etnografia visual nos pontos de prostituição femininos em Goiânia/GO e Aparecida de Goiânia/GO” o autor Joab Júnio da Silva traz as dimensões de "perigo", "risco" e "ameaça" e se questiona como podem ser descritas na etnografia. Nas duas produções percebemos um diálogo profícuo entre etnografia e cartografia, o que nos leva a pensar o quanto o desenho pode ser uma forma de escritura política e afetiva em momentos nos quais é preciso (re)pensar nossos trabalhos de campo. 
Concluímos apontando que todos os trabalhos aqui apresentados atentam para o cruzamento de diversos marcadores sociais da diferença como gênero, raça, etnia, sexualidade, geolocalização e classe social. O Brasil, bem como grande parte do mundo em seus confrontamentos e resistências, depara-se com a possibilidade de incorporar presenças, negras, femininas, indígenas, norte e nordestinas, plurisexuais, não apenas como objetos de estudo e minorias a serem atendidas, mas também na busca de soluções inclusivas de não expropriação de suas agendas, lutas e corpos. A partir destes múltiplos lugares de subjetividades, existências e contestações podemos construir um diálogo intercultural com e sobre outros sujeitos que vivenciam lutas políticas e indenitárias estetizadas na arte contemporânea e na cidade.

Essa é a esperança que depositamos no presente dossiê.

\section{REFERÊNCIAS}

ABALOS JUNIOR, J L. As politicas da criatividade: graffiti, street art e desenvolvimento urbano-cultural no Brasil e em Portugal. Tese (Doutorado em Antropologia Social). Instituto de Filosofia e Ciências Humanas, Universidade Federal do Rio Grande do Sul, Porto Alegre, 2021.

ADERALDO, G “Territórios, mobilidades e estéticas insurgentes. Refletindo sobre práticas e representações coletivas de realizadores visuais nas metrópoles contemporâneas", Cadernos de Arte e Antropologia, Vol. 6, No 2, pp. 31-48, 2017.

ADERALDO, G; OTÁVIO R. "Deslocando fronteiras, notas sobre intervenções estéticas, economia cultural e mobilidade juvenil em áreas periféricas de São Paulo e Lisboa”, Horizontes Antropológicos, vol.22, n.45, pp. 279-305, 2016.

AGIER, M. "Do direito à cidade ao fazer-cidade. O antropólogo, a margem e o centro". Mana, v. 21, n. 3, pp. 483-498, 2015.

BOURRIAUD, N. Estética relacional, São Paulo: Martins, 2009.

BUSER, M., BONURA, C., Fannin, M. and Boyer, K. "Cultural activism and the politics of place-making”. City 17(5), pp. 606-627, 2013. 
CAMPOS, R; SARROUY, A. “Juventude, criatividade e agência política”, TOMO, 37,pp. $7-42,2020$.

CAMPOS, R; PAVONI, A; ZAIMAKIS, Y. Political Graffiti in Critical Times: The Aesthetics of Street Politics. Oxford \& New York: Berghahn Books, 2021

CAMPOS, R. "A parede é a coisa política por excelência” In Manuel Bogalheiro, Isabel Babo e João Sousa Cardoso (org.) Expressões Visuais Disruptivas no Espaço Público, Lisboa, CICANT - Edições Universitárias Lusófonas, no prelo, 2021.

CAMPOS, R.; SIMÕES, J. A.; PEREIRA, I. "Digital media, representations and practices of recent activism in Portugal". Communications: The European Journal of Communication Research 43(4),pp. 489-507. 2018.

DE CERTEAU, Michel. A invenção do cotidiano. $3^{\text {a }}$ edição. Petrópolis: Editora Vozes, 1998.

DELGADO, M. “Artivismo y pospolítica. Sobre la estetización de las luchas sociales en contextos urbanos", Quaderns-e, Institut Català d'Antropologia, Número 18 (2) Any 2013 pp. 68-80, 2013.

DI GIOVANNI, J. R. “Artes de abrir espaço. Apontamentos para a análise de práticas em trânsito entre arte e ativismo", Cadernos de Arte e Antropologia, Vol.4, No2, pp.13-27, 2015 .

ECKARDT, F. "Planning for Creativity? The Concept of the "Creative City" and the Case of the Documenta in Kassel". Reclaiming Public Space through Intercultural Dialogue, v. 17, pp. 223, 2018.

FERREIRA DA SILVA, D. “Ler a arte como confronto". Logos, v. 27, n. 3, 2020.

GLISSANT, É. Poétique de la Relation. Paris: Gallimard, 1990.

GONÇALVES, F. do N. “Arte, ativismo e tecnologias de comunicação nas práticas políticas contemporâneas”. Contemporânea, v. 10, n. 2, pp. 178-193, 2012.

HALL, S. Cultura e representação. Rio de Janeiro, RJ: Ed. PUC-Rio: Apicuri, 2016.

HANKINS, K. "Creative democracy and the quiet politics of the everyday". Urban Geography 38(4), 502-506, 2017. 
HARGREAVES, I; HARTLEY, J. The Creative Citizen Unbound. How Social Media and DIY Culture Contribute to Democracy, Communities and the Creative Economy. Bristol: Policy Press. 2016.

JURIS, J. "Embodying Protest: Culture and Performance within Social Movements". In B. Baumgarten, P. Daphi, and P. Ullrich (eds.), Conceptualizing Culture in Social Movement Research. Basingstoke: Palgrave Macmillan, 82-104, 2015.

LEFEBVRE, H. O Direito à cidade, Centauro Editora, 2006.

MIGNOLO, W. D. "Aiesthesis decolonial”. CALLE 14: revista de investigación en el campo del arte, v. 4, n. 4, pp. 10-25, 2010.

MOMBAÇA, J. “A plantação cognitiva”. In: MASP Afterall - Arte e Descolonização. São Paulo: Museu de Arte de São Paulo, 2020.

MOTEN, F; HARNEY, S. "Pretitude e governança". Atos de fala. Rio de Janeiro: Telemar, pp. 27-33, 2016.

MOULD, O. Urban subversion and the creative city. Routledge, 2015.

PARK, R. “A cidade: sugestões para a investigação do comportamento humano no meio urbano", in G. Velho, O fenômeno urbano, Rio de Janeiro, Zahar, 1967.

RANCIÉRE, J. A partilha do sensivel: estética e política. São Paulo: Editora: Editora 34. 2000 .

. El espectador emancipado. Ediciones Manantial, 2008.

. Nas margens do político. Lisboa: KKYM, 2014.

. O Desentendimento: política e filosofia. São Paulo: Ed. 34, 1998.

. O mestre ignorante: cinco lições sobre a emancipação intelectual. Autêntica, 2002.

ROLNIK, S. "Desentranhando futuros". ComCiência, Campinas, n. 99, 2008. Disponível em: $<$ http://comciencia.scielo.br/scielo.php?script=sci arttext\&pid=S1519-

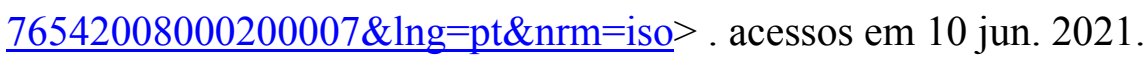


ROSA, R. "Notas sobre o coletivismo artístico no Brasil". RUA, Campinas, SP, v. 12, n. 1,pp. 27-35, 2015.

SANDOVAL C.; LATORRE G. "Chicana/o Artivism: Judy Baca's Digital Work with Youth of Color". In A. Everett (ed.), Learning Race and Ethnicity: Youth and Digital Media. Cambridge, MA: The MIT Press, 81-108, 2008.

SIMMEL, Georg. A ruína. In: SOUZA, Jessé e ÖELZE, Berthold. Simmel $\boldsymbol{e}$ a modernidade. Brasília: UnB. 1998.pp. 137-144.

ST JOHN, G. Protestival: "Global Days of Action and Carnivalized Politics in the Present”, Social Movement Studies, v.7, n.2, pp. 167-190, 2008

TLOSTANOVA, M. La aesthesis trans-moderna en la zona fronteriza eurasiática y el anti-sublime decolonial". Calle 14: revista de investigación en el campo del arte, v.5, n.6, pp. 10-31, 2011.

VERGARA, C. "Corpo transgressão: a violência traduzida nas performances do Coletivo Coiote, Bloco Livre Reciclato e Black Blocs”, Cadernos de Arte e Antropologia, Vol. 4, No 2, pp. 105-123, 2015.

Recebido: 01/06/2021

Aprovado: 02/06/2021 